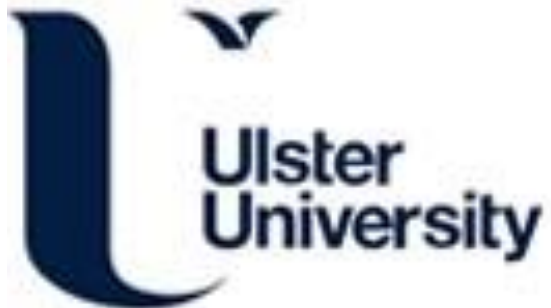

\section{Cage and Tudor as Process}

Casey, R. (2017). Cage and Tudor as Process. Contemporary Music Review, 35(6), 670-685. https://doi.org/10.1080/07494467.2016.1282648

Link to publication record in Ulster University Research Portal

\section{Published in:}

Contemporary Music Review

\section{Publication Status:}

Published online: 01/03/2017

DOI:

10.1080/07494467.2016.1282648

\section{Document Version}

Author Accepted version

\section{General rights}

Copyright for the publications made accessible via Ulster University's Research Portal is retained by the author(s) and / or other copyright owners and it is a condition of accessing these publications that users recognise and abide by the legal requirements associated with these rights.

\section{Take down policy}

The Research Portal is Ulster University's institutional repository that provides access to Ulster's research outputs. Every effort has been made to ensure that content in the Research Portal does not infringe any person's rights, or applicable UK laws. If you discover content in the Research Portal that you believe breaches copyright or violates any law, please contact pure-support@ulster.ac.uk. 


\title{
Cage and Tudor as Process
}

\section{Rob Casey}

Rob Casey (2016) Cage and Tudor as Process, Contemporary Music Review,

\begin{abstract}
I mean to isolate here one of the signature concepts ascribed to the music of John Cage, not only in the writings of historians and musicologists, but one to which the composer repeatedly linked his music: the concept of process. It is a noun that permeates much discourse surrounding the creative arts and perhaps paradoxically it might be that due to its ubiquity, musicologists feel little compulsion to clarify what they wish it to mean. It is, in a sense, a musicological problem that hides in plain sight. Composers in the $20^{\text {th }}$ century began to use the term process, not as a mere descriptor of creative action but as a defining characteristic of their music. Cage was foremost amongst his contemporaries in this regard. The fact that the concept may constitute a differentiating stylistic feature of $20^{\text {th }}$ century music is of less interest to me than the promiscuous coupling routinely engineered by commentators between the term and any number of disparate musical practices. However, that is less interesting still than the fact that Cage's own use of the term offers an opportunity to discuss, in a systematic way, many of the musicological problems that Cage's music raises and which it is the task of musicologists to try and answer. I shall explore the concept of process within the context of some of these issues. My thesis is that 'process' is habitually linked with the practice of Cage without sufficient regard its implications for our understanding of his music. Close analysis of the term will help elucidate some of the main features that characterise his work and may unearth tools that aid us in crafting answers to questions regarding authorship and ontology in the music of John Cage.
\end{abstract}

'If you begin, as I do, not with the notion of making objects, but the idea of making a process, and if that process is in fact, silent, which is to say the sounds are unwilled... then the silence takes on an entirely different significance. In other words, the music is evident constantly, whether there are sounds, or silences' (Cage, 1963).

\section{Tudor as Musical Subject}

In 1951 John Cage composed Music of Changes for the pianist David Tudor with whom he had become recently acquainted. The exact circumstances of their first meeting are not clear, but in the decade that followed, composer and pianist fostered a working partnership that would become arguably the most significant to emerge from the American avant-garde. As Martin Iddon has rightly 
observed, had Cage and Tudor never met 'it would probably have been impossible to speak of the 'New York School' of composers - brief though that union may have been - and the history of postwar music would surely have been radically, almost unimaginably different (Iddon, 2013a, p. 1).' It was during this first decade of their association that the artistic ties binding composer and pianist were strongest. Although he continued to perform works by Cage, Tudor did not add any Cage pieces to his solo repertoire following the composition of Variations II in 1961 (2013a, p. xii). What becomes clear from extant letters and interviews is that throughout the period from Music of Changes (1951) to Variations II (1961), Cage engaged Tudor to shape not only realisations of his scores but the aesthetic thinking from which those works were borne. What marked Cage and Tudor's association as unique in the early development of post-war music was that Tudor became not only the interpreter but the subject of Cage's compositions. Cage came to delight in formulating musical puzzles that demanded the forensic attention of this particular pianist's very particular temperament. For Tudor was no mere passive executor of Cage's compositional will. He addressed the often considerable challenges presented by Cage's notation in ways often unforeseen by the composer. As a result, established concepts of authorship, musical work and performer became irrevocably blurred. For Cage, the work and the performer (usually Tudor) would become indistinguishable. Cage said of their first musical enterprise that '[a]t that time, [Tudor] was the Music of Changes '(Cage and Charles 1981, p. 178 as cited in Iddon, 2013a, p. 40). The strategies that Tudor devised for realising Cage's scores would consequently have striking repercussions for Cage's development as a composer. Cage's devotion to Tudor the musician and the man, would provide impetus for Cage to cultivate his concept of 'composition as process' which would, in turn, guide his experiments with musical indeterminacy. What follows is an examination of the Cagean theory of musical process; the way the composer experimented with implementing it in his work; Tudor's role in shaping Cage's conceptual and practical understanding of 'process' and its subsequent influence on Cage's approach to indeterminacy.

\section{Misunderstanding Composition as Process}

Throughout the decade leading up to Variations II, Cage would state that his aim was to create compositions that were not musical objects in the European tradition as he saw it, but processes. ${ }^{1}$ When invited by Alfred Steinecke to deliver a series of five seminars at the Darmstadt Summer School in 1958, Cage enthusiastically responded by telegram: 'YES SUBJECT COMPOSITION AS PROCESS $=$ CAGE +1 ' $\left(\right.$ Iddon, 2013b). ${ }^{2}$ Tudor had been invited to accompany Stefan Wolpe to

1

John Cage interviewed by Jonathan Cott, https://archive.org/details/CottInterviews. Accessed June $20^{\text {th }} 2016$ 
Darmstadt in 1956 and was influential in bringing, not just Cage, but a whole generation of young American composers to the attention of the faculty (Beal, 2007). In 1958 Tudor returned with Cage and performed music by Cage, Christian Wolff, Stockhausen and Bo Nilsson during the seminars Cage gave there (2007, p. 81). It is not clear that the five seminars went ahead as Steinecke planned but we know that Cage, accompanied by Tudor, did in the end deliver a three-part lecture series under the heading Composition as Process (Iddon, 2013b). Cage was consistent in his devotion to process as the underlying philosophy of his music. Yet, for a number of reasons, the concept would garner much less attention from those attending his Darmstadt lectures than his use of chance operations.

The three lectures comprising the series were titled Changes, Indeterminacy and Communication. The content of the lectures spoke to Cage's aesthetic by providing his audience with both a conceptual and applied understanding of his art. Cage related his ideas not only through the conventional semantic discourse common to all lectures, but by manipulating, according to chance procedures, the syntactical and morphological structures of his delivery of the text. For example, in his final lecture, Communication, Cage would periodically pause to light a cigarette, take a drag, extinguish the cigarette and then resume his lecture. Cage had, he said, formulated 'by chance operations indications of when, in the course of performance, I am obliged to light a cigarette' (Cage, 2011, p. 41). In Cage's teaching the dialectic nature of theory and praxis is extinguished. He and Tudor are both practicing and preaching his message. Perhaps more significant than the, probably inevitable, scepticism that greeted Cage at Darmstadt was the misunderstanding of what he stood for. Labels that were frequently bestowed upon his music by contemporaneous critics were 'accident', 'freedom' 'Dada' and, perhaps the most egregious contradiction of Cage's aesthetic: 'improvisation' (Iddon, 2013b). That his lectures went some way to confusing his position could be blamed variously upon his audience, the composer himself and, as Iddon has pointed out, the sometimes misleading German translation of Cage's texts (2013b, p. 216). Although posterity has granted Cage's theories greater clarity and acceptance, the overarching theme that gave his Darmstadt lecture series its title, that of 'Composition as Process', has received comparatively scant attention. In light of how Cage and Tudor conducted these lectures it is not surprising that what resonated most with observers was the performative aspect of his delivery and the seeming equanimity, or even indifference, with which Cage greeted all outcomes of the chance procedures he was using to construct his music and the content of his lectures. If Cage, the composer, was unwilling to exercise his artistic judgement in selecting and organising his materials then it is hardly surprising that some European critics were reluctant to engage their faculties in anything other than summary dismissals of the American interloper. "Today it's only thanks to chance that he continues to "compose", sneered Antoine Goléa in response to Cage's lectures. 'Nothing is meaningful', he continued, 'only the current gag' (Iddon, 
2013b, p. 221). Critics such as Goléa found it difficult to reconcile themselves with the apparent meaningless that chance operations conferred upon Cage's music. A consequence of their resistance to the apparent purposelessness of his music is that indeterminacy rather than process became the primary focus of discussions of Cage. The fixation upon chance was understandable. The composer had reinforced associations made between his concept of process and non-intention, disorder, and unpredictability. Cage had given the second of his three lectures the title 'indeterminacy' and it is true to say that indeterminacy was a recurrent theme of his presentations and was for many in attendance the most unorthodox feature, and therefore the main talking point, of his music. However, as evidenced by the overall title of the lecture series, indeterminacy was being used by Cage in service of a primary goal: 'Composition as Process.' Cage was not championing indeterminacy as a cause; he viewed it as a symptom of his faith in the true musical process that he was developing in tandem with Tudor. If we wish, therefore, to come to terms with how Cage's music proposed to supplant the intolerable diktats of European orthodoxies, it is imperative to undertake a close examination of the 'process' that Cage was advocating in 1958.

\section{Europe and Process}

In the twentieth century the term 'process' came to be regarded as a key feature of many disparate styles of musical practice. The concept proved to be unusually compatible with a range of competing schools of thought, finding a prominent role in discourse relating to the Second Viennese School, Darmstadt School, New York School, Minimalism plus any number of bifurcations, subsets or splinterings thereof. Indeed, an argument could be made that dedication to 'process' offered the closest thing to consistent feature of new music in a century of perennial renewal. The terms by which we might understand the fundamental nature of twentieth century musical process were not generally made explicit in the recorded views of composers or critics. ${ }^{3}$ In any case, it is important to note that both commentary and practice are not representative of a single point of view and thus will never be philosophically self-consistent. There is no doubt, however, that 'process' was regarded as a divisive feature of post war serial composition. We may infer two distinguishing features of the term as it was understood by those attending the Cage's lectures in Darmstadt in 1958: 1. The suppression, to at least some extent, of the subjective will of the composer and 2: The fact that processes extend in time.

The seemingly increased marginalisation of the subjective will in favour of formal processes was an increasingly contentious feature of the avant-garde. Concern had arisen amongst commentators that serial composers were playing the role of mere stenographers, responsible only for the dutiful cataloguing of a process played out at a remove from their artistic judgement. Ernst Thomas lamented 
that Stockhausen's Kontra-Punkte 'follows an ordering principle, which is imprisoned by its material: he himself does not compose, rather he obeys the intellectually independent material' (as cited in Iddon, 2013b, p. 98) Armin Schibler declared somewhat hysterically, 'the work with rows threatens to become an abstract process which suppresses every declaration of humanity' (as cited in Iddon, 2013b, p. 98). Critics responded to the rise of objective processes with scepticism, if not naked hostility. The primary asset for a composer of such music was not aesthetic flair and imagination but the rather dry fastidious attention to detail that normally accompanies a facility for numeracy and accurate transcription. For these critics, processes kept imagination, and even humanity, in abeyance functioning only in opposition to compositional will and the inspired spirit. Adorno advocated for creative intervention in the process, for the composer to subject the numerical systems to a certain amount of artistic inspiration (Iddon, 2013b). The application of systems and procedures was characterised as a form of indentured servitude, if not outright imprisonment of the creative soul. Reservations about the pre-eminence of objective process over subjective will were not exclusive to critics and audiences. Referring to new music featured at Darmstadt in 1953/54, Boulez criticised the 'disparity between what was written and what was heard: there was no sonic imagination, but quite simply an accumulation of numerical transcriptions quite devoid of any aesthetic character' (Boulez, 1976, p. 64). Composers such as Boulez and Nono warned against the schematic sterility of process. 'Iddon writes ' $[\mathrm{I}] \mathrm{t}$ was precisely the 'human element' that Nono had sought to highlight directly against process -driven composition' (Iddon, 2013b, p. 115). Formal systems common to serial music, the kind that necessitates the working through of mathematical operations, require that a set of rules be followed; what Douglas Hofstadter refers to as the 'Requirement of Formality' (Hofstadter, 1979 , p. 33). For critics of purely objective processes the resulting music is not so much created, but derived or produced as if by a machine. Processes also exist in nature in the absence of or sometimes in direct conflict with man: erosion or plate tectonics to give two examples. It is true to say that whether they are found in nature or in machines; processes are commonly unmoved, as Schibler warned, by 'declarations of humanity'.

In light of the accusations of inhumanity that encircled the Darmstadt school, it is critical to recognise that Cage's commitment to process and his desire to suppress his will as a composer was not symptomatic of a wish to exclude human intervention from his music; quite the opposite. In the second of his Darmstadt lectures, Indeterminacy, Cage warned against music that is more 'inhuman than human' citing his composition Music of Changes as an offending example (Cage, 2009, p. 179). Although Cage had relied upon chance procedures when composing Music of Changes, the resulting score conformed to conventional notation practice in that it was fixed. The fact it had originated via 'inhuman' chance operations, combined with the control that the determinate notation exerted upon the performer, lent the piece, Cage felt, an 'alarming aspect of a Frankenstein monster (2009, p.179). Just as Cage was uncomfortable with the absolute authority exerted by European composers over their 
work, he was also discomfited by the similarly draconian hold the chance operations that gave rise to Music of Changes would have over any performance of the piece. The performer is, according to Cage, unable to identify with an immutable work whose nature had been determined prior to the performer's knowledge of the score. The identity of the composition in either case is therefore bound up with the identity of the composer. Fixed scores whether constructed via chance operations or those more traditionally conceived, serve to exert control over the performer. Cage regards the imbalance that characterises the relationship of the composer and performer to a work as an appalling consequence of the European tradition; a consequence that the compositional processes of Music of Changes cannot escape. The performer of Music of Changes or a European masterpiece Cage says, is unable 'to perform from his own centre but must identify himself insofar as possible with the centre of the work as written' $(2009,179)$. Giving oneself over to a work in this manner is, for Cage, commensurate with submitting oneself to the tyranny of a dictator. Cage's close collaboration with Tudor afforded him the opportunity to try and address these misgivings in his own work. He wished to compose music the performance of which was free of the spectre of tyrannical diktat or inhuman control. Cage's solution: process. The noun 'process' is elusive, a skeleton key term that is a good fit for almost any set of actions directed toward the creation of an artistic work. It weighs heavy in the lexical toolkit of music commentators but is not often made sense of in its own right.

\section{Performing Process through Time}

Iddon suggests that the key feature that distinguished the American from the European composers was the American desire to move away from the composer as central figure in order to emphasise instead the role of the listener. The aim of the Americans, Iddon writes, 'was to place the listener at the heart of the experience, seeking a unique hearing on behalf of each listener and dissolving distinctions between listening in 'life' and in 'art' (Iddon, 2013b, p. 214). It is noteworthy that of the human trichotomy associated with instrumental music- composer; performer; listener - the performer goes unremarked in Iddon's summation of the American aesthetic. In response it might be argued that the term 'listener' does not preclude the performer from its gamut. Even if this is the case, subsuming performance within broader listenership diminishes the critical role performers (and Tudor in particular) played in shaping this music and the thought processes from which it grew. In his lectures Cage declared his desire to re-instate human experience in art (Cage, 2009, p. 179). The humanity Cage sought to mine, in creating his piano works at least, resided in the lived, indeterminate, experience of David Tudor. Cage did not agree with critics' characterisation of the relationship obtaining between process and humanity as antithetical. He believed that, with regard to indeterminate music, that the 'action of the players is productive of a process' (2009, p. 184-185). Tudor himself was the resource upon whom Cage considered true musical process to be contingent. To fully understand the basis for this belief, it is necessary to turn from the concerns about the objectivity of musical processes to the second key identifying feature of processes: time. 
Perhaps the most incontestable feature of processes is that they persist in time. This persistence distinguishes both serial and Cagean process from the 'inspiration' so often regarded as the catalytic agent of Classical and Romantic composition. Inspiration is a subjective punctual occurrence in time most often associated with adjectives such as 'flash', 'burst' and 'sudden'. Early biographies of Mozart were quick to cultivate the mythology that compositions were in the habit of appearing to him fully formed, and that his task as a composer was merely to transcribe these apparitions as and when they presented themselves (Solomon, 1995, p. 117). A process, such as those undertaken by Tudor in realising Cage's often opaque scores, by contrast, emphasises extension through time. Processes attract wearisome adjectives like 'lengthy', 'arduous' and 'tedious', a requirement to work through a series of linear steps. Of course processes are not the only things that occupy time. Actions, events and states all have temporal qualities that seem intuitively distinct from processes. Attempts to devise a reliable system whereby we may differentiate processes from actions, events and states continue to generate philosophical debate beyond the scope of this paper. However, some of the debate around these theories may provide a useful lens through which to view Cage and Tudor's collaborative work, perhaps bringing clarity to Cage's misunderstood conception of musical process.

\section{Indeterminacy, Time and Process}

Discussion of time within Cage's music is bound up with his use of indeterminacy. It was Cage's evolving approach to indeterminacy, shaped throughout by his working relationship with Tudor, which was most illustrative of the composer's dedication to process. As their musical association developed, beginning with Music of Changes (1952) and, to all intents and purposes, culminating with Variations II (1961), Tudor was increasingly afforded greater interpretative and, by extension, creative responsibility. It is instructive to examine this development in their professional relationship. Iddon has divided the Cage and Tudor working association into three roughly contiguous phases: determining the determinate; determining the indeterminate; (in)determining the indeterminate (Iddon, 2013a). These headings describe how chance elements gradually came to suffuse the entire continuity extending from composition through performance. To begin with Cage's scores were fully determined. Tudor was required, with some help from mathematician Hans Rademacher, to devise formulae by which he could implement the unorthodox tempo markings presented in the score Music of Changes, but this was a question of interpretative strategy and did not satisfy Cage's growing desire for truly open form. Iddon refers to this period in which Tudor was tasked with finding fixed solutions to fixed problems as 'determining the determinate' (2013a).

It is evident from his lectures that Cage was keenly aware that the 'chance operations' that characterise his compositional approach in this period come burdened with finality. An operation connotes a goal or boundary after which the operation is no more. Cage came to look upon prescriptive scores, and the boundary they demarcated, as an encumbrance upon the performer, a 
suppression of individuality symptomatic of an authoritarian musical culture. From what he said on the matter, it is clear that he believed this burden, one imposed by fixed notation, could be lifted by the adoption of a true musical process. Given the term 'process' remains loaded with ambiguity it may be useful to apply increased precision to this discussion's, thus far, rough outlining of its meaning.

Efforts in the philosophical literature to systemise distinctions of verb-types such as 'processes', 'occurrences', 'events', 'states', 'achievements' and 'activities' have rested largely upon linguistic factors; namely the time-schema implied by grammatical structure. Zeno Vendler proposed a system by which verb types were accorded membership of one of four ontological categories based primarily on whether the statement exhibited a continuous or non-continuous form (Vendler, 1957). Activities (run, push, swim) and states (desire, love, hate) are, Vendler said, identifiable by the presence of a continuous verb form. Accomplishments (run-a mile, compose a fugue) and achievements (recognise, find, win) are, by contrast, exhibitive of non-continuous verb-types. Achievements contain the implied culmination of an act and can be dated but do not, in Vendler's system, have duration. Accomplishments have both duration and an implicit end point. States are not actions at all, they have no internal dynamic quality though they do endure over a stretch of time. Vendler's 'activity' verbtype category is closest to Cagean process in that activities, under this system, do not imply any anticipated upshot or fixed outcome. We might presume that Vendler would suggest 'Composition as Activity' as the appropriate title for Cage's Darmstadt lectures. Other theorists have, however, taken issue with the classification of occurrences based on verb-types, claiming they can only be usefully applied in limited cases (Mourelatos, 1978). Consider the statements:

(1.) David played a Mozart Sonata

(2.) David played a little Mozart

The verb 'played' is identical in both statements but the temporal nature of the predicate seems intuitively different. Sentence (1) contains the implied outcome that distinguishes an event. In sentence (2) the amount played is inherently indefinite, there is no presumed outcome attached suggesting it is a process or 'activity' predicate in the Vendlerian sense. In these examples, it is not the verb-type but the presence of a count or mass noun that determines the process/event character of the predicate. Examples of count nouns are dog, tree, book, sentence, sonata. They can be distinguished by the fact that they have a plural form that does not modify the meaning of the singular form; they can take the indefinite article 'a', 'a tree' 'a sonata'; cardinal numbers, 'two books', 'four dogs'; they may be subject to the informal version of the existential quantifier, 'there is at least one'; and can be used with the adjectives 'many', 'few' 'several.' Mass terms like 'snow', 'wine' and 'music' cannot be used with the adjectives 'many' and 'few'. They cannot be pluralised without a modification of meaning: 'the wines in the supermarket' implies types of wine; nor can the modifying adjectives that are used with count nouns be applied to mass nouns, they take instead adjectives like 
'little', 'much', 'few', enough' (Mourelatos, 1978). In sentence (1) the object, 'a Mozart Sonata', is a count noun, signifying, according to Geoffrey Leech, an event predication (as cited in Mourelatos, 1978, p 424). Sentence (1) communicates an occurrence, a complete whole. In sentence (2) the verbobject 'a little Mozart' is a mass noun, meaning we have a process predication on our hands. The sentence 'He played a little Mozart' alludes to an unbounded temporal quantity that Leech suggests could prompt the question 'How long did you play?' The question 'How long did you play?' does not fit the statement 'I played a Mozart Sonata.' You might inquire how long it took which signifies an occurrence in time rather than a process through time which the mass term implies. Leech's system for distinguishing events and processes resonates with Tudor's performances of Cage's piano music. Earlier determinate works such as Music of Changes, Water Music and Two Pastorales fit Leech's criteria for an event. The statement 'David Tudor played Music of Changes' is not syntactically different from 'He played a Mozart Sonata.' It would be more appropriate therefore to ask 'How long did it take Tudor to play Music of Changes?' than 'How long did Tudor play Music of Changes?' As with the Mozart example, if Tudor did not play the full score we cannot say that he had played Music of Changes, only that he had performed an extract as he often did during the lectures Cage delivered in Darmstadt. A true performance of Music of Changes is a punctual occurrence in time, predicated upon completion. It is, in short, an event. Tudor's realisation of later works such as Solo for Piano (1957-58) from the Concert for Piano and Orchestra are more at odds with Leech's definition of 'event'. Intrinsic to Solo for Piano is that there is no requirement for Tudor to perform the full score for us to be able to say that 'He played Solo for Piano.' Solo for Piano would be reconstituted in many forms in a variety of settings, functioning as accompaniment, a stand-alone work or as a solo part within an orchestral setting. Tudor's preparatory sketches for the piece's Town Hall premiere in New York plan for a duration of 23 minutes and 15 seconds (Iddon, 2013a, p. 73). Subsequent performances given at the Village Vanguard lasted less than five minutes (2013a, p.74). When Solo for Piano was documented in combination with the collection of stories Cage read for the recording titled Indeterminacy, Tudor had to find a way to match the ninety-minute duration of Cage's monologue. Despite the extremes in duration that Tudor's selective reading of the score permitted, it is not true to say that in any of these circumstances only a segment of Solo for Piano was performed. Holzaepfel pointedly arrests any impulse to categorise the shorter performances as extracts, referring to the Village Vanguard performances as 'abbreviated forms of the plans for the Town Hall concert' (as cited in Iddon, 2013a, p.74). As with the abbreviation of a word, though the structural integrity may change, none of the meaning (or the meaninglessness Cage's case) is lost. Given the flexibility that is afforded time in Solo for Piano and the care Tudor takes in determining a range of durations for different settings it is not at all inappropriate to respond to the declaration 'I played Solo for Piano' with the question 'How long did you play?' The question 'How long do I play?' was foremost in Tudor's mind in any given performance of the piece moving Solo for Piano closer to Leech's definition of a process than an event. 
Cage's music was returned to him by Tudor in sometimes unpredictable forms, often serving as a direct challenge to the aesthetic that Cage avowed. Tudor's calculated and rigorous application to the unorthodox demands of these scores was such that it thoroughly tested the philosophical foundations upon which the music was built. The pianist's actions repeatedly interrogated Cage's philosophy, doubting that it might ever find its true expression in practice. Cage absorbed these lessons, continually revising his compositional approach in light of Tudor's interpretations. In the pieces that followed Music of Changes and Two Pastorales, Cage was driven to shore up the perceived failure of the music to allow the pianist to 'perform from his own centre.' These failings were uncovered in large part by Tudor's working practice. The composer-performer relationship in this instance was not conventionally linear but iterative; the outcome of each collaboration became input for the next, until the working relationship began to generate complex, indeterminate results. It was necessary for Cage to maintain a prolonged association with Tudor in order that these iterations could be played out and his aspirations of composition as unbounded process could be brought nearer fruition.

It is a commonly held view that Tudor was engaged as a kind of solver of puzzles set by Cage and that the composer would devise scores containing challenges that would keep the pianist interested (Iddon, 2013a, p. 67). Cage wrote his music in full knowledge of Tudor's unwavering capacity for formulating methodical, focused and creative responses to any musical challenge that engaged his formidable intellect and pianistic skill. In recalling Tudor's pervasive influence on the American avant-garde of the time and the daunting prospect of writing for someone of his preternatural talent, Christian Wolff observed that 'when a piece was turned over to David, there was simply no anxiety. You didn't worry, you knew that something would happen. My main anxiety would be more that I had made something that wasn't good enough (to interest him) (Holzaepfel, as cited by Thomas, 2010, p. 53). Cage's notation necessitated the application of a mind of considerable diligence and fastidiousness partly because Cage realised that Tudor had both in rare abundance. His work always took stock of Tudor's capacities and proclivities. In 1981 Cage remarked:

'In all my works since 1952, I have tried to achieve what would seem interesting and vibrant to David Tudor. Whatever succeeds in the works I have done has been determined in relationship to him.... David Tudor was present in everything I was doing' (Cage and Charles, 1995, p. 178).

Tudor's preparatory notes reflect the pianist's commitment to determining solutions to Cage's puzzles. In the case of Music of Changes, Tudor's notes ran to more than 100 pages (2013a, p. 40). He never relented from this meticulous approach to preparing Cage's scores. However, symptomatic of this score-as-puzzle approach to notation was that once Tudor 'solved' a puzzle, drawing up his own score from which he would perform, he would not revisit the Cage original in search of alternate outcomes (2013a). Cage's score for Solo for Piano comprises eighty-four different types of notation, 
each with an accompanying letter or letters that are explicated by a key at the front of the score.

Prefatory instructions direct that 'a program made within a determined length of time (to be altered by a conductor, when there is one) may involve any reading, i.e. any sequence of parts or parts thereof'. Of the eighty-four notations, Tudor chose to interpret only those that were distinct. He eliminated repetitions or variations of notation types, thus reducing the total number to sixty three (Iddon, 2013a, p. 67). It seems that Tudor could see no point in expending further effort in search of solutions to an already solved puzzle. Given that Tudor was the de-facto performer of all of Cage's keyboard works during this period, his determination of Cage's indeterminate scores weakens their claims on process. It is true that any other performer could return to Cage's notation and draft any number of varying interpretations, but these pieces were written for Tudor. They were, as Cage made clear, puzzles devised with one particular player in mind.

What this meant for Cage was that his once indeterminate music would, just like those authoritarian works he censured, become determinate. In the works that followed Music of Changes, Cage himself took responsibility for the calculations that he had, in Music of Changes and Two Pastorales, entrusted to Tudor. In Water Music (1952) and 34'46.776" for a pianist (1954) he notated directly the temporal structure of the music so that performances could be realised from the original score.

Perhaps by effectively abandoning the puzzles he set in Music of Changes, Cage was tacitly endorsing Tudor's disinclination for revisiting solutions already provided to the questions posed by that particular score. It seems apparent therefore that Cage was not so much interested in the answers to the puzzles present in the notation of Music of Changes. Of interest, for Cage and Tudor were the steps taken in arriving at those answers, the process. Asking Tudor to perform the same procedures in determining the timing of events in subsequent compositions held little appeal. Though the parametric values may have been subject to change from piece to piece, the actions taken in determining the mensural structure from new variables would have remained the same. Working through the same procedures with different starting variables would result only in the challenge becoming a mere chore; not a means by which to hold Tudor's interest.

\section{Events within a Process}

By 'solving' the riddles set by Cage's ambiguous graphic notation and the often gnomic instructions with which they were accompanied, Tudor winnowed a field of possible actions to a single determined outcome. As both Vendler and Mourelatos have argued, in the backward shadow cast by a concluding action, process becomes event (Vendler, 1957: Mourelatos, 1978). The outcome of any given performance of these works is foreseen and repeatable. The resulting fixed scores moves away from the true process that Cage conceived and closer to what Lydia Goehr refers to as a nominalist conception of musical work (Goehr, 2007). Fixed notation sheds its internal dynamism, no longer 
admitting change, absenting musical works to a timeless realm and thus failing to fulfil the criteria of a truly boundless process.

There is a further dichotomy illustrative of Cage's consideration of events and process that exists within his music, one which should give us pause. It is readily apparent in Tudor's realisations of Solo for Piano. In preparing Solo for Piano Tudor favoured notations that contain what he referred to as 'single-icti' (Iddon, 2013a, p. 75). Cage had introduced the term in the instructions for Water Music, directing the performer to articulate chords 'as a single ictus.' Cage meant for the performer to underscore the disconnected nature of the note aggregates punctuating the unfolding sonic environs, thus distancing his music from the antecedent-consequent phraseology that characterised European music. Tudor's realisations are themselves exhibitive of Cage's wish that his music be comprised of isolated moments in time. During his preparation of Music for Piano 1-20 (1952-53) Tudor adopted the habit of excising the empty sections of staves from the score. The note events that remained upon the page were surrounded by empty space giving a visual impression of the aural archipelago that Cage sought in performance. The remaining note aggregates do not endure or collectively describe continuity; they represent punctual occurrences within a persisting process. Tudor made this aesthetic central to his realisation of much of Cage's music including Music for Piano 1-20, Winter Music and Solo for Piano (2013a, p. 51). The note events described in Tudor's notation take time but do not persist in time. When preparing Cage's score, Tudor fixed the timeless 'icti' chronometrically, necessitating the use of a stopwatch in performance. In so doing Tudor fulfils two of Vendler's conditions for events, namely that they can be dated and that they do not endure.

Although Tudor takes great care to emphasise the importance of event over teleology in Cage's work, his realisations were stubbornly less accommodating of process. It seems Cage felt that by expanding the role of indeterminacy he might cast off the yoke of the composer's authoritarian presence and move nearer his aim of composition as process. By Winter Music (1957) and Solo for Piano (1958) Cage had found ways of embedding indeterminacy within his scores. A combination of graphic notation and text instruction meant that it was left to Tudor to decide upon issues of structure and pitch content. As mentioned above, the structural flexibility that these works afforded meant that Tudor could tailor them to the changing practical requirements (often related to time restrictions) of any given performance situation. However, Tudor did not adopt the same situational flexibility when it came to atomistic questions of pitch identity and placement (proportionally speaking). Tudor's habit of replacing the composer's original scores with fixed staff notation presented a notable obstacle for Cage's concept of composition as process. Where macro-structure could be adapted, micro features were largely determined and unyielding to changed circumstances. Restricting indeterminacy to questions of form was, in Cage's opinion, a failure of practice over intent, a failing that he set out to redress in subsequent works. 


\section{Overcoming Tudor's determinism}

John Holzaepfel remarked that Solo for Piano acted as a kind of fulcrum about which Cage's music of this period turned. It consolidated forms of notation that Cage had used up to Solo for Piano and anticipated those yet to come including Variations I (1958), Theatre Piece and Music for Amplified Toy Pianos (1960) (as cited in Iddon, 2013a, p. 83). The score for Variations I develops notation BV from Solo for Piano. Where the graphic is comprised of points and lines fixed upon the page in Solo for Piano, the score for Variations $I$ is not yet fixed. It is made up of a set of six transparencies each bearing either straight lines or a set of points. The performer is invited to overlay the transparencies upon one another in order to generate a composite graphic from which pitches, their dynamic characteristics and their placement in time are determined. In Variations I Cage attempts to subvert Tudor's practice of creating single fixed realisations of his work. He asks that the piece not be fully determined but that it should retain its potential for multiple outcomes. Tudor obligingly departed from convention and created a number of realisations, granting no one realisation pre-eminence over the others (2013a, p. 85). It is apparent that Cage was driven to create new strategies that would retain the indeterminate nature of process into the act of performance. While multiple realisations of a score contributed some amount of indeterminacy, it was limited in scope. A choice of which realisation to perform had to be made but that decision was made in advance of performance; the performance itself remained stubbornly fixed, known and impervious to chance. In his Indeterminacy lecture Cage expressed reservations about indeterminacy that was limited to questions of form. In a critique of Stockhausen's Klavierstuck XI, a piece in which Stockhausen invited the performer to piece together fragments, Cage declared: 'form unvitalized by spontaneity brings about the death of all the other elements of the work' (Cage, 2009, p.177). Cage argued that indeterminate form has little bearing upon the material nature of a work. If, as is the case with Klavierstucke XI, the fragments are composed in an idiomatic way then the identity of the piece is foreseen, irrespective of what fragmentary shuffling takes place. In the case of Klavierstucke XI, Cage is unequivocal, indeterminacy is 'unnecessary, since it is ineffective' (2009, p.178). Although the fragments of Kalvierstucke XI and Cage's own Winter Music could be reconstituted in a number of ways, there is a factorial limit to the possible permutations. These works exist in multiple forms but, it could be argued, they do not succeed as process. They are, like the cat in Schrodinger's thought experiment, a superposition of contradictory states, but, as with any cat, very much an object, not the process Cage was trying to compose. We must assume that although chance procedures had effectively distanced Cage's music from many European conventions, he was not wholly satisfied with indeterminacy being shut out from the performance itself.

\section{Tudor and Time Brackets}


It is somewhat ironic that it was an innovation of the fastidious Tudor which provided the biggest leap toward indeterminacy in performance: the creation of the time bracket. Despite the care taken by Cage to the contrary, works that were bound by the conventions of traditional time notation, either in Cage's original scores or latterly in Tudor's realisations, put at risk the purposelessness that Cage worked hard to preserve. Unwanted perceptions, to which the listener of European music has been conditioned, such as climaxes and points of rest, would inevitably flood in to fill the imprint left by repeated performances of an unchanging score. The time bracket however, permitted events to occur anywhere within a designated period of time. As a single event could now potentially occupy an infinite number of points within a defined temporal space, it was free of any perceived obligation to syntactical structure. Given that the time bracket preserved its arbitrariness in perpetuity, the identity or meaning of a sounding note could not be bound up in its structural relations. Tudor's growing willingness to relinquish compositional choices to the contingency of dynamic time-bound experience was further reflected in his use of electronics and his increased emphasis upon the physicality of performance. He began to notate actions rather than the sounds that might issue from those actions. As Iddon observes, this meant that Tudor's realisations were less determined than would have been the case with earlier works. In Variations I Tudor allowed himself to choose 'largely freely' the beaters and points upon the piano casing that he would strike (Iddon, 2013a, p. 91). In Theatre Piece (1960) Tudor deliberately notated physical actions that were impossible to enact, leaving the activity of finding what was possible to the performance itself (2013a, p. 91). In Variations II Tudor experimented with amplifying the piano. His remarks concerning the use of amplification indicate an appreciation of the additional layer of indeterminacy that electronics afford and which he would explore further in his own work. He observed that 'in performance the parameters can interact in unforeseen ways, \& the performance becomes a process of constant invention $\&$ re-invention of the sound events' (2013a, p.183). Iddon regards the system of live electronics and amplification that Tudor developed for Variations II as reflective of the pianist's effective elevation at this point to cocomposer (2013a, p. 187). It may have been necessary to enact such a division of authorial labour in order to realise Cage's aim of Composition as Process

Tudor's notation also began to preserve, rather than undermine, the unboundedness required of true process. As with Variations I, Music Walk (1958) expanded upon notation already used in Solo for Piano. More significantly it marked the point at which Tudor no longer, for the most part, resorted to rewriting Cage's scores in fixed staff notation. ${ }^{4}$ Instead Tudor's realisations comprise text instructions with accompanying time codes. The departure from staff notation would be maintained by Tudor through his work on Theatre Piece and Cartridge Music. It signals an effort by the pianist to retain the 
indeterminacy of Cage's notation into his own redrafted scores. Pritchett says of Music Walk that it 'had no existence as a score, but rather exists as a means of making scores - a compositional process handed over to the performer to execute' (Pritchett, 1993, p. 128). Pritchett's remarks concerning Music Walk are indicative of how Cage's work was becoming, in Tudor's hands, process in the true sense. Cage set out, he said, not to make objects but to show a process. It was a goal that did not immediately betray the obstacles in its path, but finally Cage's compositions were removing the shackles of object-hood. For Cage, in his music there is no object, only open ended temporal experience.

\section{Conclusion}

Prior, at least, to Variations II it is true that the sound palette that Tudor draws from is distinctly Cagean while the morphological structure is a product of the pianist's fastidious preparations. However if we are to make a case for Cage's compositions achieving process-hood, it is Tudor's temporally extended physical experiences that furnish the detail in any given composition and confer the process genus upon the music. In contradistinction to the view propagated by critics of the Darmstadt school, that musical process is inherently inhuman, it is the very fact of Tudor's humanness that permits Cage's music to fulfil the requirements of process. Cage tried to conceive of a methodology borne out of a concept of process; to think of the act of composition not as a catalogue of events but a more nebulous abstraction of time bound living. The theme is one of adaptation, evolution, change. Along the way identity is shed or transformed as it becomes filtered by the phenomenal experiences of the performer both on and beyond the concert platform. It is clear that Cage is more interested in how things unfold through time, than in how they fasten to the present moment. Time is articulated within experience. Time is relative, not objectively determined by a universal clock or the directions of a conductor, when there is one. It emerges from the interpenetration of collective endeavour. Cage cares not for unifying 'departures and arrivals at no matter what point at no matter what time' but the open confluence of process that remains truly indeterminate with respect to its performance. As a result of the trust each man was willing to place in the other's artistic judgement, Cage and Tudor had by the time Cage wrote Variations II re-imagined the conventions of the composer-performer dynamic and the concept of the musical work. In 1984 Cage wrote to Tudor soliciting Tudor's co-operation for a proposed biography of the pianist. It would not, Cage wrote, be 'a conventional biography but a togetherness of a variety of materials' (Iddon, 2013a, p. 194-195). Try, Cage continued, 'to find your earliest memories. Then when they get thick, go year by year. In any case, I look forward to the process of bringing this work about you into existence (2013a, p. 195). This unconsummated project might have been the natural culmination of a body of work that strove to share the identity of its subject: David Tudor. In being warped by the instability of Tudor's personal narrative, by his exploratory life of praxis, a composition, for Cage, became richer. It is not a Cage composition that is articulated in performance, nor is it philosophical 
positions regarding ego and chance. Performance presents the dynamic experience of the performer. The conceit of Cagean process was that the imperfections wrought by the flow of a life lived lends unique and interesting features to heretofore impermeable musical structures.

\section{Bibliography}

Beal, Amy C. (2007). 'David Tudor in Darmstadt', Contemporary Music Review, 26(1), 77-88

Boulez, Pierre. (1976). 'Conversations with Célestin Deliège. London: Eulenburg Books, 1976)

Iddon, Martin (2013a). John Cage and David Tudor: Correspondence on Interpretation and Performance. Cambridge: Cambridge University Press

Iddon, Martin (2013b). New Music at Darmstadt: Nono, Stockhausen, Cage and Boulez. Cambridge: Cambridge University Press

Cage, John (2011). Silence: Lectures and Writings: $50^{\text {th }}$ Anniversary Edition. Middletown, CT: Wesleyan University Press.

Cage, John and Charles, Daniel (1995), For the Birds: John Cage in Conversation with Daniel Charles. London: Marion Boyars

Cage, John (2009). Composition as Process: Indeterminacy in Audio Cultures: Readings in Modern music. Ed. Christoph Cox \& Daniel Warner. New York: The Continuum International Publishing Group

Goehr, Lydia (2007). The Imaginary Museum of Musical Works. Oxford: Oxford University Press Hofstadter, Douglas (1979). Gödel, Escher Bach: an Eternal Golden Braid. New York: Basic Books Mourelatos, Alexander P.D. (1978). Events, Processes, and States, Linguistics and Philosophy, 2(3), 415-434

Pritchett, James (1993). The Music of John Cage. Cambridge: Cambridge University Press

Schoenberg, Arnold (1987). Letters. Ed. Erwin Stein. Trans. Eithne Wilkins \& Ernst Kaiser. Berkeley: University of California Press

Solomon, Maynard (1995). Mozart: A Life. New York: Harper Collins

Thomas, Philip (2010). For Pianist: The Solo Piano Music in Changing the System: The Music of Christian Wolff. Ed. Philip Thomas \& Stephen Chase. Surrey: Ashgate Publishing Limited Vendler, Zeno (1957). 'Verbs and Times', The Philosophical Review, 66(2), 143-160

\section{Audio}


Cage, John (1963). As interviewed by Jonathan Cott. Retrieved from: https://archive.org/details/CottInterviews. Accessed June $20^{\text {th }} 2016$ 